\title{
EXTRACTION OF CRUDE ESSENTIAL FROM SENNA ALATA
}

(POKOK GELENGGANG)

\author{
Wong Yee Ching ${ }^{1 *}$ and Haziqah A. Razak ${ }^{1}$ \\ ${ }^{1}$ Faculty of Agro Based Industry, Universiti Malaysia Kelantan, Jeli Campus, Locked Bag 100, 17600 Jeli, \\ Kelantan, Malaysia.
}

\begin{abstract}
Sennaalatawas one of the herbs plants that can be used to treat the ringworm in traditional method. In this study, the sennaalata was scientifically tested to prove the traditional medicinal used. Six forms of extract were extracted by using soxhlet apparatus and continued with the appropriate methods that can extract the chemical compound of anthraquinone. The six forms of extraction included anthraquinoneaglycone, anthraquinone glycoside, anthraquinoneaglycone from glycoside, anthraquinone from crude absolute ethanol, anthraqunone from crude $n$-hexane and anthraquinone from crude ethanol $70 \%$. The extraction of six forms of anthraquinone extract as antifungal was observed by tested with two types of fungi; Tricophytonrubrum and Microsporumgypseum. The extraction from crude absolute ethanol and crude $n$-hexane to inhibit these fungi were compared to determine which type of solvent was the best to use for inhibition. This test was implemented by using well-diffusion and broth microdilution method to determine the minimum inhibitory concentration (MIC). The present of six forms of anthraquinone was examined by using Thin-Layer Chromatography (TLC).
\end{abstract}

Keywords: Anthraquinone; Dermatophytes fungi; TLC (Thin Layer Chromathography); Sennaalata; well diffusion method; broth micro-dilution method.

\section{Council for Innovative Research}

Peer Review Research Publishing System

\section{Journal: Journal of Advances in Chemistry}

Vol. 11, No. 10

www.cirjac.com

editorjaconline@gmail.com, editor@cirjac.com 


\subsection{Introduction}

Sennaalata (L.)Roxb or cassia alataL. was a medicinal plant in the family Fabaceae which has been known in Thai language as Chumhetthet. The English names were Candelabra bush and Ringworm bush. At South Africa it was native plant and can be found widely in tropical region, up to $1500 \mathrm{~m}$. In Indonesia, Philippines and Thailand, this plant can be found all over the countries, sometimes cultivated for medicinal purposes [1].Sennaalata has a flower which the flower can spikes look like golden candles when covered with unopened flower buds. The tree can reach a height of 10 to 15 feet [2]. The leaves of sennaalata contain a lot of chemical component such as phenols, tannis, saponins, alkaloids, steroids, flavonoids and carbohydrates. These chemical compounds were efficient in antimicrobial and antifungal activity. Sennaalata or Cassia alataalso has been reported to contain anthraquinone[3].Other part of Sennaalatasuch as roots, fruits and stem also consists of anthraquinone [4].Sennaalata is one of the plenty of plants that can treat ringworm which is easily spread to others just by touching [5]. Previous research showed that there were plenty of chemical compound presences in Sennaalatasuch tannis, flavonoid, phenol, alkaloids and steroid. From the phytochemical screening most of the active chromatography compound is flavonoid. However, there is no evidence that flavonoid is a main constituents of leaf extract [3]. Meanwhile, another previous research was determined the chemical compound that presence in the leaves that can react as antifungal is anthraquinone[6].

In previous research crude extract of ethanol was better than methanol use in extracting the chemical compound presence in the leaves and $n$-hexane was a good solvent in order to extract the chemical compound of leaves plants too [7]. Hence, in this experiment two types of solvents; absolute ethanol and n-hexane were used to determine which type of solvent was the best solvent can be used to extract anthraquinone

In this study, the main objectives of this research were to study the activity of antifungal by difference forms of anthraquinones extraction through well diffusion method and broth micro-dilution method. Besides to compare the activity of antifungal extracted from crude $n$-hexane and crude absolute ethanol.

\subsection{Materials and methods}

\subsection{Preparations of plants}

Sennaalata was obtained at the resident area KangarPulai, Johor Bahru. The leaves part was used in order to extract the chemical compound. The leaves were dried under the sun for about 5 days. Then the leaves were blended until it can be passing through to the sieve mesh with size $0.5 \mathrm{~mm}$. The smaller the size of the leaves, the higher the amount of chemical compound can be obtained due to have large surface area and increased solubility throughout the extraction process [8].After that, $20 \mathrm{~g}$ leaves of Sennaalata were weight to be extracted in each form of extract.

\subsection{Inoculum preparation}

Pure isolated strains of test organisms were sub-cultured on SDA until full growth with proper characteristics [6]. Cultural characteristic was observed after incubated at $260 \mathrm{C}-30 \mathrm{oC}$ for 7 to 14 days. The two types of fungi that were sub-culture wasTricophytonrubrum and Microsporium gypseum.

\subsection{Extraction of anthraquinoneaglycone and anthraquinone glycoside extracts}

The extraction was done from 8 hour reflux of the aqueous part of 20 grams of $\mathrm{S}$. alataleaf powder and $300 \mathrm{~mL}$ water; the aqueous extract was adjusted to $\mathrm{pH} 4$ with $2 \mathrm{M}$ hydrochloric acid $(0.3 \mathrm{~mL})$, and later extracted with $200 \mathrm{~mL}$ of chloroform. The collected extracts from chloroform layer was evaporated to yield anthraquinoneaglycone extract while the aqueous layer was added with $1.392 \mathrm{~g}$ of sodium bicarbonate to adjust to neutral $\mathrm{pH}$. The solution was centrifuged at $4000 \mathrm{rpm}$ for $20 \mathrm{~min}$.

The supernatant which contained anthraquinone glycoside was evaporated to dryness to give anthraquinone glycosides extract. It was evaporated by using rotary evaporator at $450 \mathrm{C}$ with $60 \mathrm{rpm}$.

\subsection{Extraction of anthraquinoneaglycone from glycosidic fraction}

The extraction was done similar to the process of anthraquinone glycosides extract except for evaporation to dryness. Ferric chloride hexahydrate solution $(50 \mathrm{~mL})$ was added to the anthraquinone glycosides extract, and then refluxed for 30 min. The solution was added with concentrated $\mathrm{HCl}(0.1 \mathrm{M}), 15 \mathrm{~mL}$ and refluxed for another 30 min and filtered after cool down. The filtrate was shaken with $200 \mathrm{~mL}$ of chloroform in a separating funnel and separated the chloroform layer, combined and washed with $200 \mathrm{~mL}$ of distilled water, then evaporated to dryness to yield anthraquinoneaglycone from glycosidic fraction. In rotary evaporator the temperature used was $250 \mathrm{C}$ with $45 \mathrm{rpm}$.

\subsection{Extraction of anthraquinoneaglycone from crude ethanol $70 \%$ extract}

S. alataleaf powder $20 \mathrm{~g}$ was extracted with $300 \mathrm{~mL}$ of $70 \%$ ethanol using a soxhlet apparatus. A portion of the crude ethanol extract was further extracted by adding $170 \mathrm{~mL}$ of water and $30 \mathrm{~mL}$ of $70 \%$ ethanol. After $10 \%$ of the solution was decrease ferric chloride hexahydrate solution which was about $50 \mathrm{~mL}$ was added, the mixture was refluxed for 30 min before adding $20 \mathrm{~mL}$ concentrated hydrochloric acid $(0.1 \mathrm{M})$ and refluxed for another $30 \mathrm{~min}$. When the mixture was cooled down, it was filtered and the filtrate was extracted with $200 \mathrm{~mL}$ of chloroform. 
The chloroform layer was combined and washed with distilled water $(200 \mathrm{~mL})$, then evaporated to dryness to yield anthraquinoneaglycone from crude ethanol $70 \%$ extract. The temperature used was $250 \mathrm{C}$ with $45 \mathrm{rpm}$.

\subsection{Extraction of crude absolute ethanol extract}

S. alataleaf powder $20 \mathrm{~g}$ was extracted with $300 \mathrm{~mL}$ of absolute ethanol. Then, the solution was evaporated at rotary evaporator with the temperature $450 \mathrm{C}-500 \mathrm{C}$ and $55 \mathrm{rpm}$.

\subsection{Extraction of crude $n$-hexane extract.}

S. alataleaf powder $20 \mathrm{~g}$ was extracted with $300 \mathrm{~mL}$ of $\mathrm{n}$-hexane. Then, the solution was evaporated at rotary evaporator with the temperature $450 \mathrm{C}-500 \mathrm{C}$ and $55 \mathrm{rpm}$.

\subsection{Well diffusion method}

Average zone diameter was done by using agar well diffusion. The size of the well use was $0.7 \mathrm{~cm}$ of the diameter. $1 \mathrm{~mL}$ from each of six forms of the extracts was diluted with $9 \mathrm{~mL}$ of Dimethyl Sulfoxide (DMSO4). The fungi that were growth with the characteristic were prepared using distilled water. $80 \mu \mathrm{l}$ of inoculum was inoculated into each of saboraoud dextrose agar plate surface layer. The agar make up for three well diffusions for three different types of extracts concentration. Three different concentrations of extract were used which were $50 \mu \mathrm{l}, 80 \mu \mathrm{l}$ and $100 \mu \mathrm{l}$.

The agar was incubated for 24 hours at $260 \mathrm{C}-30 \circ \mathrm{C}$. After 24 hours the results for the zone of inhibition area was taken. Ketoconozole was act as a positive control while distilled water used as a negative control. The way to calculate the zone of inhibition is by place the ruler under the dish and measure the diameter of the zone of inhibition. The zone of inhibition was measure to the nearest millimetre. If the fungal growth is not inhibited around the well area, the zone of inhibition is the diameter of the well area. If it is measured in $1 \mathrm{~cm}$ means it is equal with $10 \mathrm{~mm}$.

\subsection{Broth micro-dilution method}

In Minimum Inhibitory Concentration (MIC) six forms of extracts were serial dilution with Sabouraud Dextrose Broth prior inoculated into the microtiter plate wells. The dilutions that prepared were $1 \mathrm{mg} / \mathrm{mL}, 0.5 \mathrm{mg} / \mathrm{mL}, 0.25 \mathrm{mg} / \mathrm{mL}, 0.125$ $\mathrm{mg} / \mathrm{mL}, 0.0625 \mathrm{mg} / \mathrm{mL}, 0.03125 \mathrm{mg} / \mathrm{mL}$ and $0.0156 \mathrm{mg} / \mathrm{mL}$. After that, $20 \mu \mathrm{l}$ of suspended inoculum is inoculated into each of the dilution tubes. The control will be growth control (fungus and broth), control (broth only).

To identify either the solution of Dimethyl Sulfoxide, (DMSO4) contain of antifungal agent, it also tested in MIC reading which was diluted $1 \mathrm{~mL}$ of DMSO4 into $9 \mathrm{~mL}$ of SDB and inoculated with $20 \mu \mathrm{l}$ of fungus. Then, all the solution prepared was inoculated into the wells with $200 \mu$ l. According to Kaya, et al., (2012) prior the plate is incubated, the reading of OD is taken to ease calculate the percentage of inhibition. After that, the plate was incubated for 24 hours then OD reading was taken again.

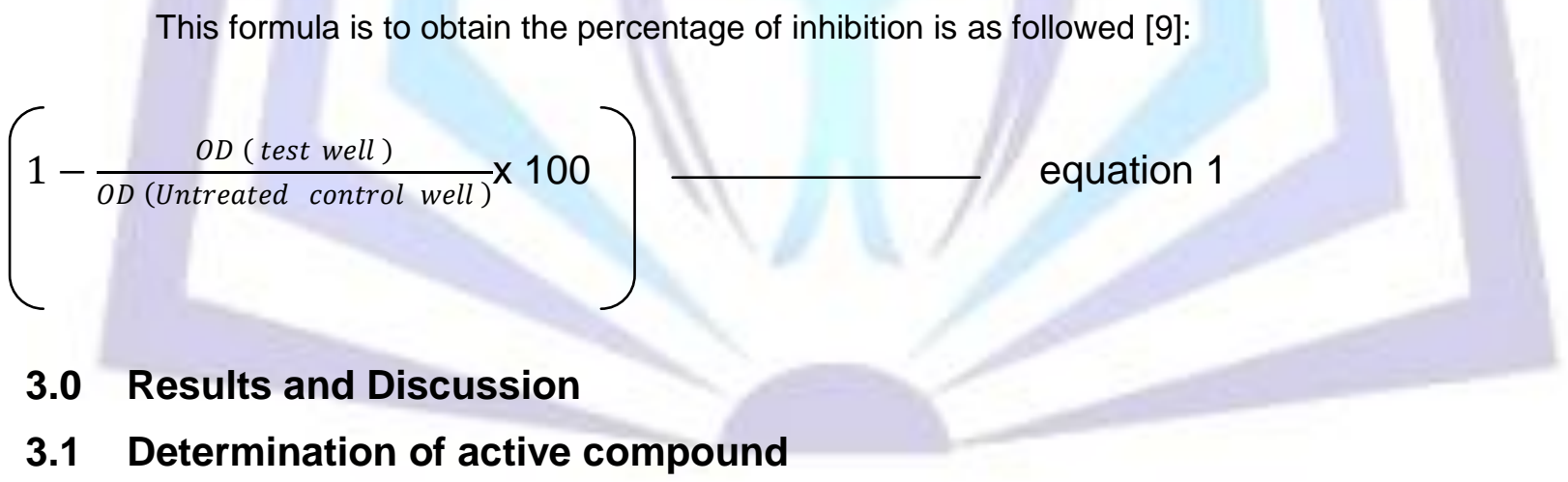

Determintion for active compound in sennaalatawas by using Thin Layer Chromatography (TLC) plate. Thin layer chromatography was used to detect the presence of anthraquinone in each of the extract form. The size of the thin layer aluminium plate was $7 \mathrm{~cm} \times 10 \mathrm{~cm}$. The presence of anthraquinone in each form of the extract on the plate, was by spraying with $10 \%$ methanolic $\mathrm{KOH}$. The presence of anthraquinone will turn the extract form to red-pink. From figure 10 , the presence of anthraquinone compound was detected at the TLC plate. After spraying with methanolic $10 \% \mathrm{KOH}$ the presence of chemical compound, anthraquinone can be determine by red-pink colour on the plate [10] [11].The yellow orange colour was also detected to attribute antraquinone formation[11]. It also showed that all form of extracts have the presence of antraquinone

The hRf values were obtained by using this formula [12] :

$\mathrm{hRf}=\frac{\text { Distance travelled by solute from origin }}{\text { Distance travelled by solvent from origin }}$

equation 2 
From table 1 the hRf value for extract form of anthraquinoneaglycone was 24 . For anthraquinoneaglycone from glycoside was 16 . For anthraquinone glycoside was 16 . For anthraquinone from crude ethanol $70 \%$ was 15 . For anthraquinone from absolute ethanol were 33 and for anthraquinone from crude $\mathrm{n}$-hexane were 28 . The hRf values of main components were determine by comparing with the $\mathrm{hRf}$ value of anthraquinone standard [10]. The standard of hRf value for Rhein is 15 (hR $=15)$, Aloe-emodin $(\mathrm{hRf}=23.3$ ) and Emodin ( $\mathrm{hRf}=38.3)$. From the standard $\mathrm{hRf}$ value for anthraquinone, we can determine that the $\mathrm{hRf}$ value for all forms of extract were near to the standard anthraquinonehRf value.Anthraquinoneaglycone $(\mathrm{hRf}=24)$ near to standard Aloe-emodin. Anthraquinoneaglycone from glycoside $(\mathrm{hRf}=$ $16)$, Anthraquinone glycoside $(\mathrm{hRf}=14)$ and anthraquinone from crude ethano $70 \%(\mathrm{hRf}=15)$ near to standard $\mathrm{Rhein}$ $(\mathrm{hRf}=15)$. For anthraquinone from absolute ethanol $(\mathrm{hRf}=33$ ) near to standard Emodin $(\mathrm{hRf}=38.3)$ and for anthraquinone from crude $\mathrm{n}$-hexane was $(\mathrm{hRf}=28)$ near to standard Aloe-emodin $(\mathrm{hRf}=23.3)$. From the comparison can be detected that the dot red-pink colour was exactly the anthraquinone chemical compound presence in the extraction form of antraquinone.

\subsection{Zone of inhibition}

Table 2 shows the zone of inhibition of two types of dermatophyte fungi which were Tricophytonrubrum and Microsporumgypseum. The effectiveness of each form of extract was tested by using well diffusion method. In welldiffusion method it can determine the average of zone of inhibition of each extracts. For extract $A$, which was anthraquinoneaglycone, Tricophytonrubrumshows better respond to this extract compare M.gypseumwith $1.47 \mathrm{~cm}$ zone of inhibitonat $80 \mu \mathrm{g} / \mathrm{mL}$. For M.gypseum the best zone of inhibition for extracts A was at $100 \mu \mathrm{g} / \mathrm{mL}$ with $1.8 \mathrm{~cm}$ zone of inhibitions.

For extract B, which was anthraquinone glycoside, generally M.gypseum more respond to this extract. The large size of zone inhibition at extract B was $1.6 \mathrm{~cm}$ at $100 \mu \mathrm{g} / \mathrm{mL}$. For T.rubrum the best size of zone of inhibiton at extract B was 1.2 $\mathrm{cm}$ at $100 \mu \mathrm{g} / \mathrm{mL}$ too. For extract $\mathrm{C}$, which was anthraquinoneaglycone from glycoside, T.rubrum more respond to this extract compare M.gypseum. The size of zone of inhibition was large at $100 \mu \mathrm{g} / \mathrm{mL}$ for both of these fungi which were 1.5 $\mathrm{cm}$ and $1.43 \mathrm{~cm}$.

In extract D, which was anthraquinone from absolute ethanol,T.rubrumalso shows better respond to this extract compare M.gypseum. The size of zone of inhibition was large at $80 \mu \mathrm{g} / \mathrm{mL}$ with $1.73 \mathrm{~cm}$. While for M.gypseum the size of zone of inhibition was large at $100 \mu \mathrm{g} / \mathrm{mL}$ of the extract which was $1.06 \mathrm{~cm}$. For extract $\mathrm{E}$, which was anthraquinone from nhexane, M.gypseum shows better response towards this extract. Both fungi show large size of inhibition at $100 \mu \mathrm{g} / \mathrm{mL}$ of this extract which was $1.43 \mathrm{~cm}$ from M.gypseum and $1.37 \mathrm{~cm}$ from T.rubrum.

In the extraction of anthraquinoneaglycone from crude ethanol $70 \%$, with $\mathrm{F}$ labelled, T.rubrum shows the size of zone of inhibition was large at $100 \mu \mathrm{g} / \mathrm{mL}$ with $1.57 \mathrm{~cm}$ and M.gypseum was at $1.43 \mathrm{~cm}$. Hence, from all forms of extract of antraquinone, the size of zone of inhibition was the best at $100 \mu \mathrm{g} / \mathrm{mL}$ except for antraquinone from crude absolute ethanol which show best zone of inhibition area at concentration $80 \mu \mathrm{g} / \mathrm{mL}$. The largest size of zone of inhibition was extraction from anthraquinoneaglycone with $1.8 \mathrm{~cm}$ diameter at $100 \mu \mathrm{g} / \mathrm{mL}$ towards M.gypseum.

Table 3 shows the comparison activity of antifungal between crude absolute ethanol and crude $n$-hexane. At concentration $50 \mu \mathrm{g} / \mathrm{mL}$ the zone inhibition area crude n-hexane was larger than absolute ethanol which was $1.16 \mathrm{~cm}$ and $1.17 \mathrm{~cm}$. At concentration $80 \mu \mathrm{g} / \mathrm{mL}$ the zone inhibition area for absolute ethanol was larger than crude $\mathrm{n}$-hexane $(1.73 \mathrm{~cm})$ which for T.rubrum but for M.gypseumn-hexane shows greater size of inhibition area $(1.23 \mathrm{~cm})$. At $100 \mu \mathrm{g} / \mathrm{mL}$ the zone of inhibition area for $n$-hexane was larger than absolute ethanol which was $1.43 \mathrm{~cm}$ and $1.37 \mathrm{~cm}$.

From this result, it can conclude that the activity of antifungal between absolute ethanol and crude $n$-hexane was dependent on the concentration extract used and currently seem that the extract from crude $n$-hexane show better antifungal activity at $50 \mu \mathrm{g} / \mathrm{mL}$ and $100 \mu \mathrm{g} / \mathrm{mL}$ compare to extract from crude absolute ethanol. At $80 \mu \mathrm{g} / \mathrm{mL}$ extract from crude absolute ethanol show great zone of inhibition area compare to $80 \mu \mathrm{g} / \mathrm{mL}$ which from crude $\mathrm{n}$-hexane.

\subsection{Minimum Inhibitory Concentration}

Table 4 and 5 show the percentages of inhibition of antifungal by different concentration. Table 4 show the percentage of inhibition for Tricophytonrubrum and 5 for Microsporumgypseum. From table 4 all form of extracts show the higher percentage of inhibition at $1 \mathrm{mg} / \mathrm{mL}$ which was $98.51 \%, 82.50 \%, 99.84 \%, 93.24 \%, 95.46 \%$, and $97.14 \%$. The other concentrations of extracts also show positive percentage of inhibition but in lower percentage. The percentage of positive control for Tricophytonrubrumwas $97.69 \%$. The positive control used in this study was ketoconazole.

The highest percentage of inhibition of the extract for Tricophytonrubrumwas anthraquinoneaglycone from glycoside, $99.84 \%$. The lowest percentage of inhibition was antraquinone glycoside with percentage $82.50 \%$. From table 5 all form of extract show higher percentage of inhibition at $1 \mathrm{mg} / \mathrm{mL}$ which was $99.70 \%, 79.02 \%, 99.73 \%, 84.79 \%, 84.68 \%$ and $99.28 \%$. The percentage of positive control for Microsporumgypseumwas $82.51 \%$. The highest percentage of inhibition of the extract for Microsporumgypseum was anthraquinoneaglycone from glycoside which was $99.73 \%$.

The extraction from anthraquinoneaglycone from glycoside also show the best extract for MIC compare to other extraction [6]. The other concentrations of the extract also show positive percentage of inhibition but in middle and lower percentage. The lowest percentage of inhibition was at extract anthraquinone glycoside with only $79.02 \%$. Anthraquinoneaglycone extract from glycoside show the highest percentage of inhibition for both of fungi. The percentage of inhibition for positive control was higher at T. rubrum compare to M. gypseum. Each form of extractions showed positive inhibition towards both of dermatophytes fungi. 
From table 6 the percentage of inhibition of Tricophytonrubrumfor crude n-hexane was higher than crude absolute ethanol which was $95.46 \% \%$ at $1 \mathrm{mg} / \mathrm{mL}$. While at table 7 the percentage of inhibition of Microsporumgypseum was higher at extract crude absolute ethanol which was $84.79 \%, 1 \mathrm{mg} / \mathrm{mL}$. It can be conclude that, the types of fungi were reacted with different types of extracted form used.

\subsection{CONCLUSION}

Sennaalata can be extracted by using soxhlet extraction. The same amount of sennaalata used at each of the extract forms can determine the best extract form produce anthraquinone in order to inhibit the fungi by average of zone inhibition and also minimum inhibitory concentration. The presence of anthraquinone can be detected by using TLC by spraying it with methanolic $10 \% \mathrm{KOH}$. From all forms of extract of antraquinone, the size of zone of inhibition was the best at 100 $\mu \mathrm{g} / \mathrm{mL}$ except for antraquinone from crude absolute ethanol which show best zone of inhibition area at concentration 80 $\mu \mathrm{g} / \mathrm{mL}$. In minimum inhibitory concentration the best form of extraction to inhibit T.rubrum and M.gypseum was athraquinoneaglycone from glycoside. The percentage of inhibition of T.rubrum was $99.84 \%$ while for M.gypseum was $99.73 \%$. The concentration used for the highest percentage of inhibition was at $1 \mathrm{mg} / \mathrm{mL}$. For extracted from crude $\mathrm{n}$ hexane and absolute ethanol it can be conclude that, the types of fungi were reacted with different types of extracted form used.

\section{Acknowledgement}

The authors express their sincere appreciation to Faculty of Agro Based Industry, Universiti Malaysia Kelantan, Jeli Campus for the financial support and a good facilities which made this study possible.

\section{References}

[1] Wandee, G., and Peeranuch, M., (2009). Original Article Standardized Senna Alata. Leaf Extract J Health Res. 23(2):59-64.

[2] Chong, K. Y., Tan,H.T.W., and Corlett R.T., (2009). Raffles Museum Of Biodiversity Research, National University Of Singapore, Singapore, A Checklist Of The Total Vascular Plant Flora Of Singapore: Native, Naturalised And Cultivated Species

[3]Owoyale, J.A., Olatunji, G.A., Oguntoye, S.O., (2005). Antifungal And Antibacterial Activities Of An Alcoholic Extract Of Senna Alata Leaves. Journal Application Science Environment, 9 (3) 105 - 107.

[4]Ogunjobi, Abiala,A. A., and Abiala, M. A., (2013). Antimicrobial Activity Of Senna Alata And Phyllanthus Amarus, 7(2), 198-202.

[5]Abubacker, M.N., Ramanathan R., and Senthil, K.T., (2008). In Vitro Antifungal Activity Of Cassia Alata Lin Flower Extract. Natural Product Radiance, 7(1),6-9.

[6]Mansuang, W. U., Pavena, K., and Wandee, G.,(2010). In Vitro Evaluation Of Antifungal Activity Of Anthraquinone Derivatives Of Senna Alata. J Health Res,24(3), 117-122.

[7]Nuha, C.M., (2010) Phytochemical Analysis Of The Leaves Of ChromolaenaOdorata (Asteraceae), 2-24

[8]Zubairi, S.I., Sarmidi, M.R., Aziz,R.A.,(2014), The Effects of Raw Material Particles Size, Types of Solvents and Solvent-to-Solid Ratio on the Yield of Rotenone Extracted from Derris ellipticaRoots, SainsMalaysiana 43(5) 707-713.

[9]Nurhayatie, S., Nasir, M. D., Leslie, T.T.L., Chong, P., (2013). Anti-Hyphal Formation Property Of Allicin In Suppression Of Aspergillus Fumigatus Growth, Malaysian Journal Of Microbiology, Vol 9(3), Pp.245-252

[10]Sakulpanich, A., and Wandee, G., (2009). Leaf Extract For Alternative Source Of Laxative Drug. Global Science Book, Determination Of Anthraquinone Glycoside Content In Cassia Fistula, 3(1), 42-45.

[11]Marisa, D.C.O., Giusepina, N., Antônio S., And Márcia, R., B., (2007) Detection Of Anthraquinones And Identification Of 1,4-Naphthohydroquinone In Cell Suspension Cultures Of Rudgea Jasminoides (Cham.) Müll. Arg. (Rubiaceae), Revista Brasil. Bot., V.30, N.1, P.167-172.

[12]Rajinder, S., C., Priyanka, J., (2002) A Thin Layer Chromatograpic Method For The Species Identification For Grass Leaf Stain, Malaysia Journal Of Forensic Sciences. Pg 20-29 


\section{List of figures}

Figure 1

Figure 2

Figure 3

Figure 4

Figure 5

Figure 6

Figure 7

Figure 8

Figure 9

Figure 10

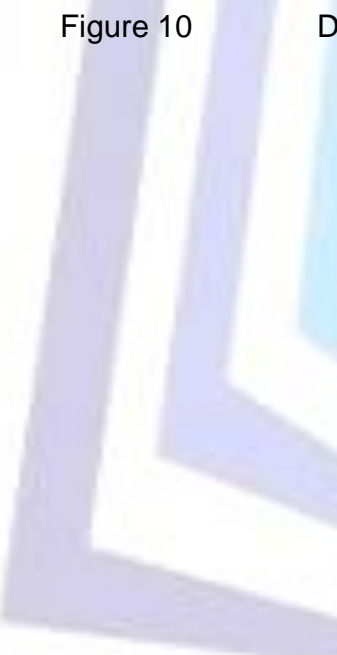

\section{Flower of Sennaalata}

\section{Leaves of Sennaalata}

Chemical structure of anthraquinone

Chemical formulae and chemical structure of anthraquinone

Preparation of anthraquinoneaglycone, anthraquinone glycoside and anthraquinoneaglyconefrom glycoside

Preparation of anthraquinoneaglycone from crude ethanol $70 \%$

Preparation for anthraquinone from crude ethanol extract

Preparation for anthraquinone from crude $n$-hexane extract

Show the present of chemical compound in each form of extract

Detection of anthraquinone chemical compound

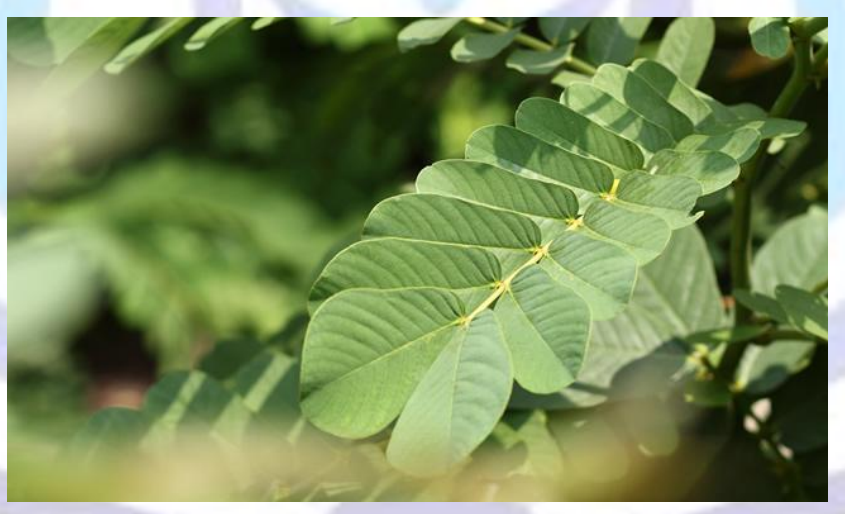

Figure 1: Flower of Sennaalata

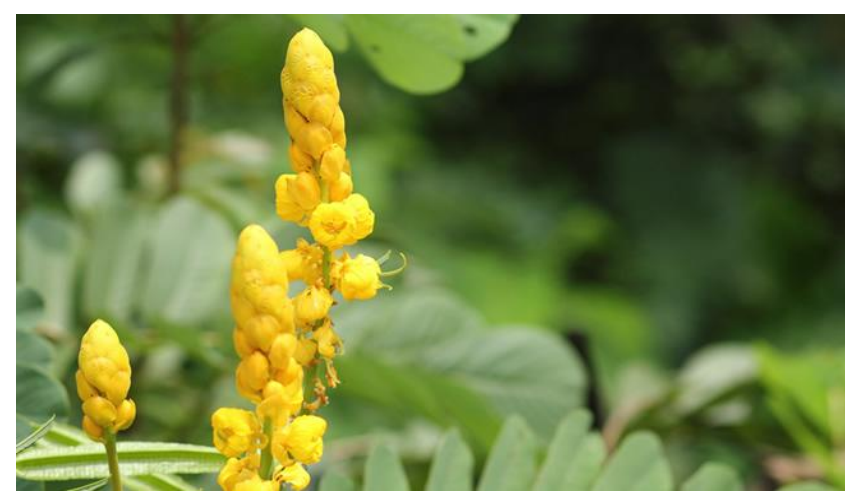

Figure 2: Leaves of Sennaalata 
<smiles></smiles>

Anthunes

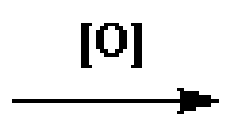<smiles>O=C1c2ccccc2C(=O)c2ccccc21</smiles>

Anthroquinone (oxidixed derivative)

Figure 3: Chemical structure of anthraquinone<smiles>[R1]c1cc(O)c2c(c1)C([2H])c1cc([R2])cc(O)c1C2=O</smiles>
anthurote

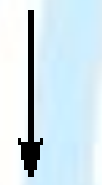

Encodin anthrotie

Chrysaphutiol anthrone

Aloe-Enoditie anthrone

Fheir arithrone
$\mathrm{CH}_{2} \mathrm{OH}$

$\mathrm{COOH}$<smiles>[R1]c1cc(O)c2c(c1)C(=O)c1cc([R8])cc(O)c1C2=O</smiles>

anthroquitione

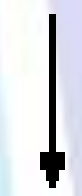

$\mathrm{F}_{2}$

$\mathrm{OH}$

Entoditi

Figure 4: Chemical formulae and chemical structure of anthraquinone. 


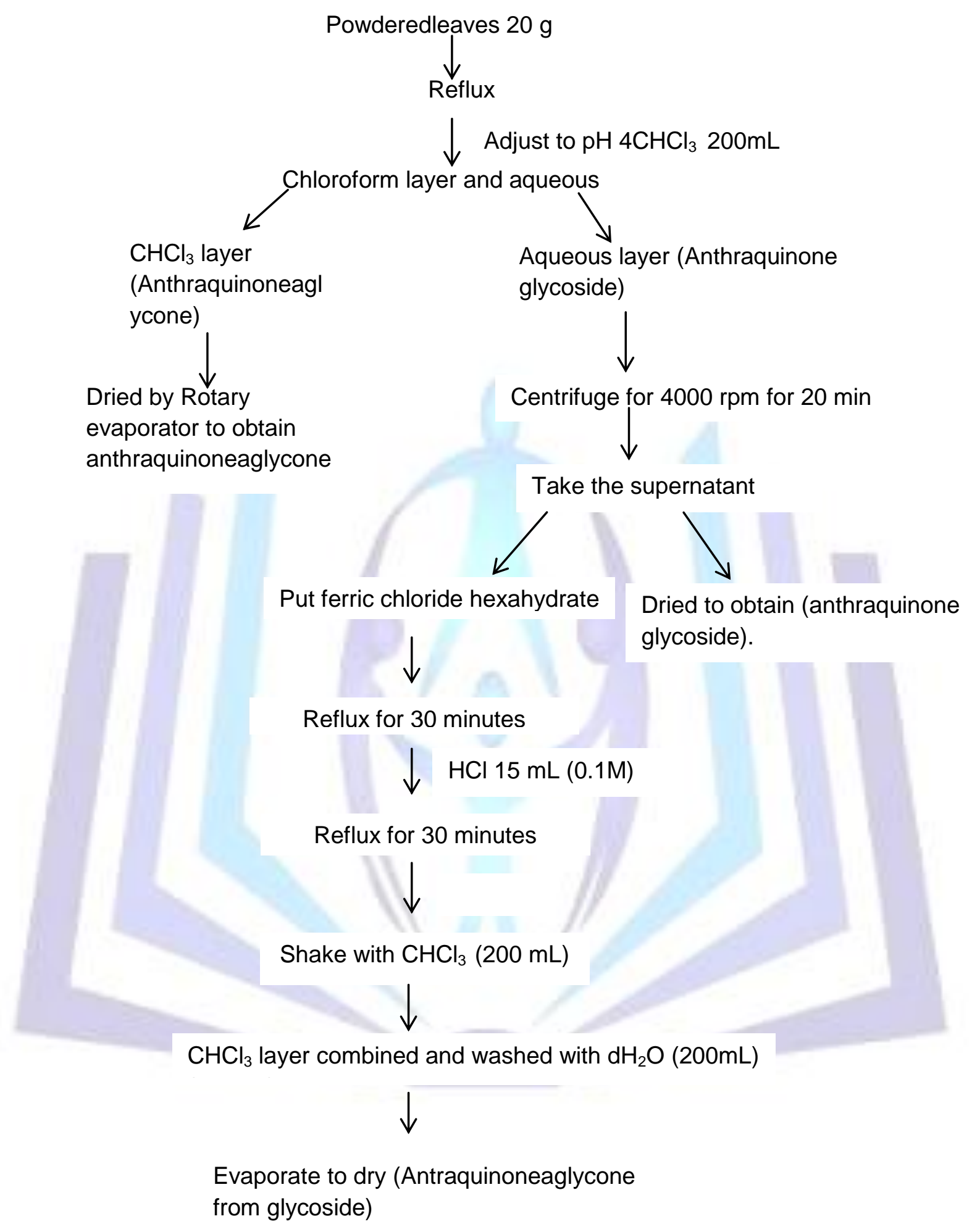

Figure 5: Preparation of anthraquinoneaglycone, anthraquinone glycoside and anthraquinoneaglyconefrom glycoside 


\section{Powderedleaves $20 \mathrm{~g}$ \\ $\downarrow$}

Extract to dryness to yield crude ethanol $70 \%$ by using $300 \mathrm{~mL}$ of<smiles>C1CCCCC1</smiles>

Add $170 \mathrm{~mL} \mathrm{dH} \mathrm{H}_{2} \mathrm{O}+30 \mathrm{~mL} 70 \%$ ethanol

$\downarrow$ Add ferric chloride hexahydrate

Refluxed 30 minutes

$\downarrow$ Add $20 \mathrm{mLHCl}(0.1 \mathrm{M})$

Refluxed 30 minutes

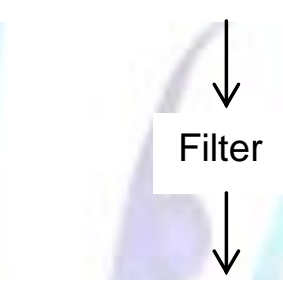

Shake with $\mathrm{CHCl}_{3}(200 \mathrm{~mL})$

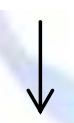

$\mathrm{CHCl}_{3}$ layer combine and wash with $\mathrm{dH}_{2} \mathrm{O}$

$$
\downarrow
$$

Evaporate with rotary evaporator to yield (anthraquinoneaglycone from crude ethanol $70 \%$ )

Figure 6: Preparation of anthraquinoneaglycone from crude ethanol $70 \%$ 
$\downarrow$

Prepared $300 \mathrm{~mL}$ of absolute ethanol

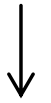

Extract to dryness to yield

(antraquinone from crude

Ethanol extract )<smiles>[AlH2][VH2]</smiles>

Test for zone of inhibition area at SDA

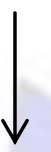

Test for MIC

Figure 7: Preparation for anthraquinone from crude ethanol extract

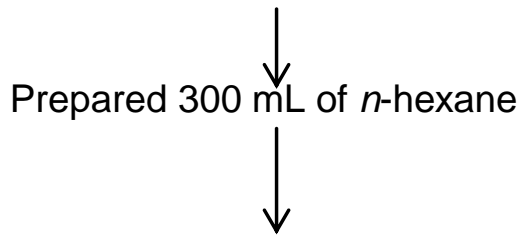

Extract to dryness to yield (Antraquinone from crude $n$ hexane extract )

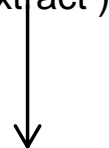

Test for zone of inhibition area at

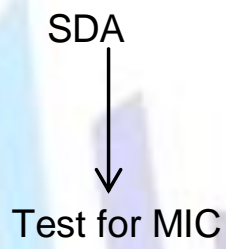

Figure 8: Preparation for anthraquinone from crude $n$ hexane extract

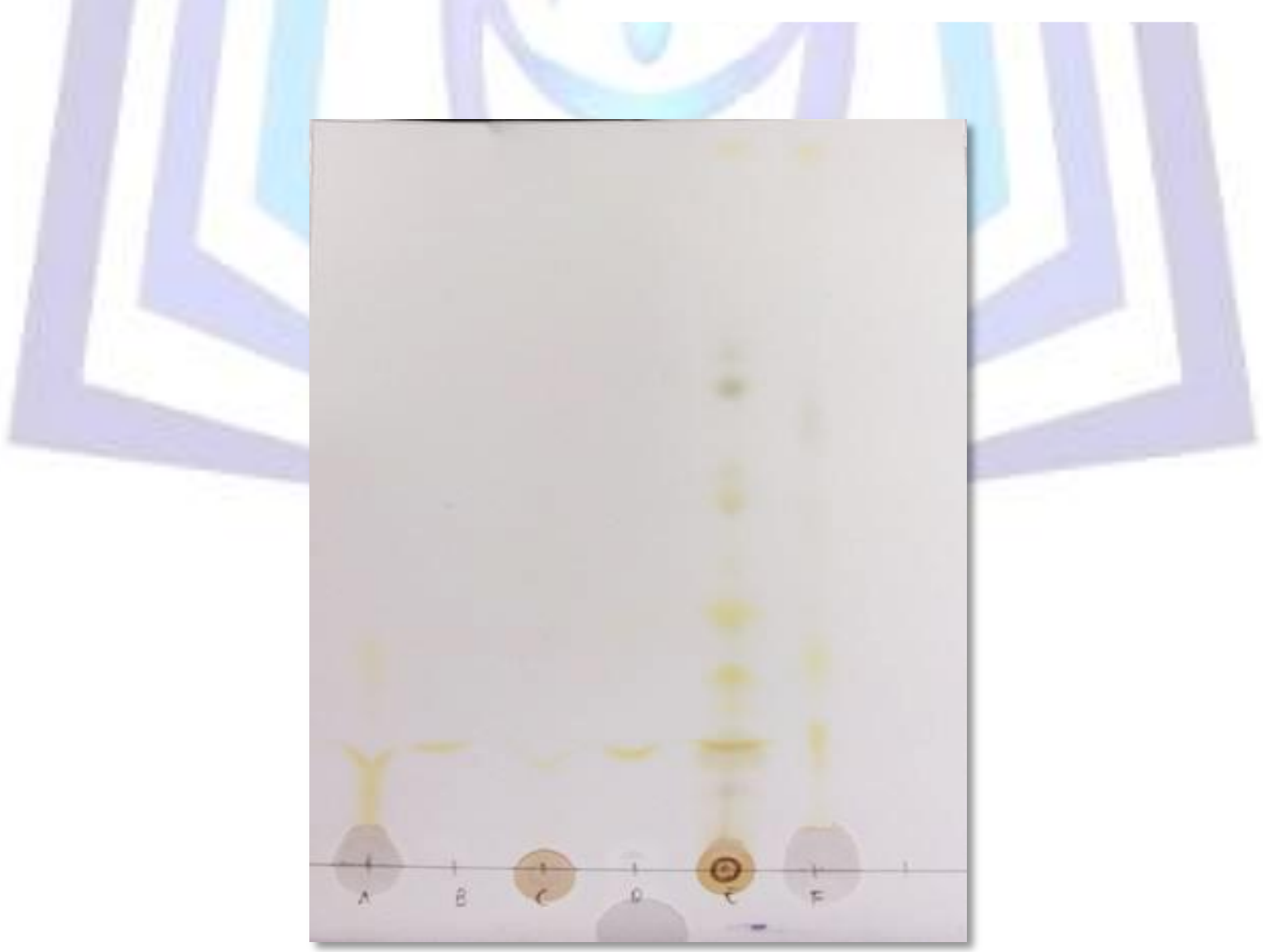

Figure 9: Show the present of chemical compound in each form of extract 


\section{Lists of tables}

Tables

1

2

3

4

5

6

7

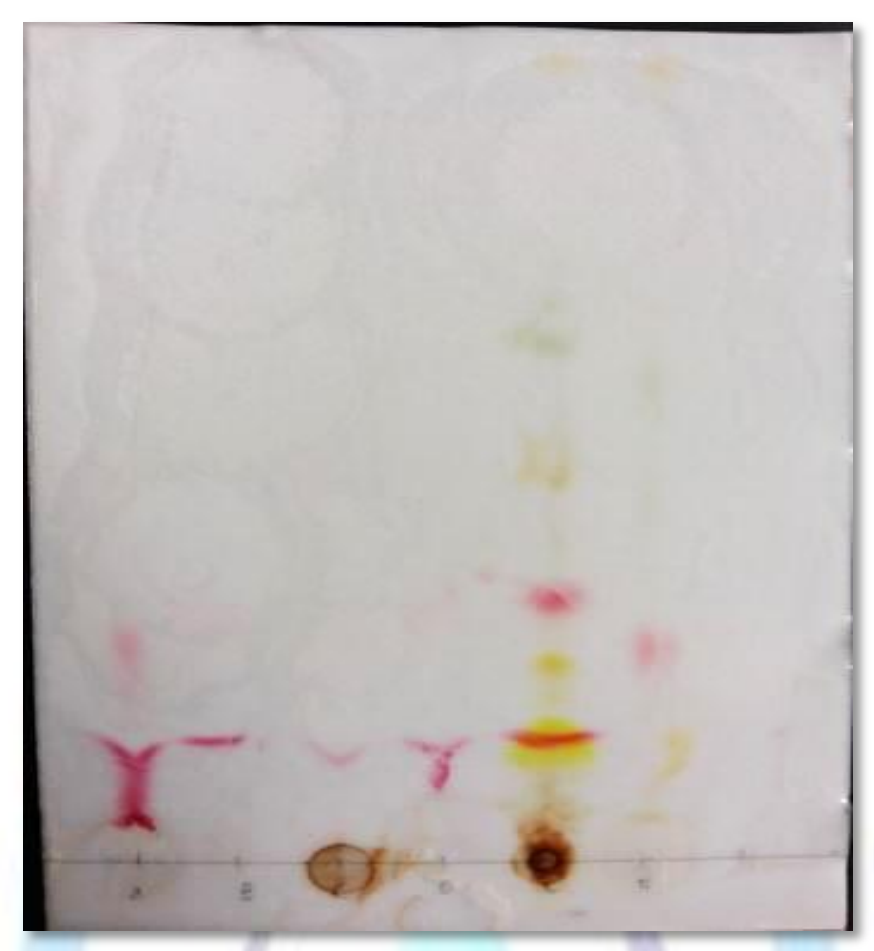

Figure 10: Detection of anthraquinone chemical compound

Show the hRf value for each of the extract form.

Average zone of inhibition for different form of extracts

Average of zone of inhibition for crude absolute ethanol and $n$-hexane

The percentage of inhibition of T.rubrum for each form of extracts

The percentage of inhibition of M.gypseum for each form of extracts

Percentage of inhibition of T.rubrum for crude absolute ethanol and $n$ hexane

Percentage inhibition of M.gypseum for crude absolute ethanol and $n$ hexane

Table 1: Show the $\mathrm{hRf}$ value for each of the extract form.

\begin{tabular}{lc}
\hline \multicolumn{1}{c}{ FORM OF EXTRACT } & hRf value \\
\hline A: Anthraquinoneaglycone & 24 \\
B: Anthraquinoneaglycone from glycoside & 16 \\
C:Anthraquinone glycoside & 14 \\
D: Anthraquinone from crude ethanol 70\% & 15 \\
E: Anthraquinone from absolute ethanol & 33 \\
F: Anthraquinone from crude $n$-hexane & 28 \\
\hline
\end{tabular}


Table 2: Average zone of inhibition for different form of extracts

Dermatophytes

Average zone diameter $(\mathrm{cm})$

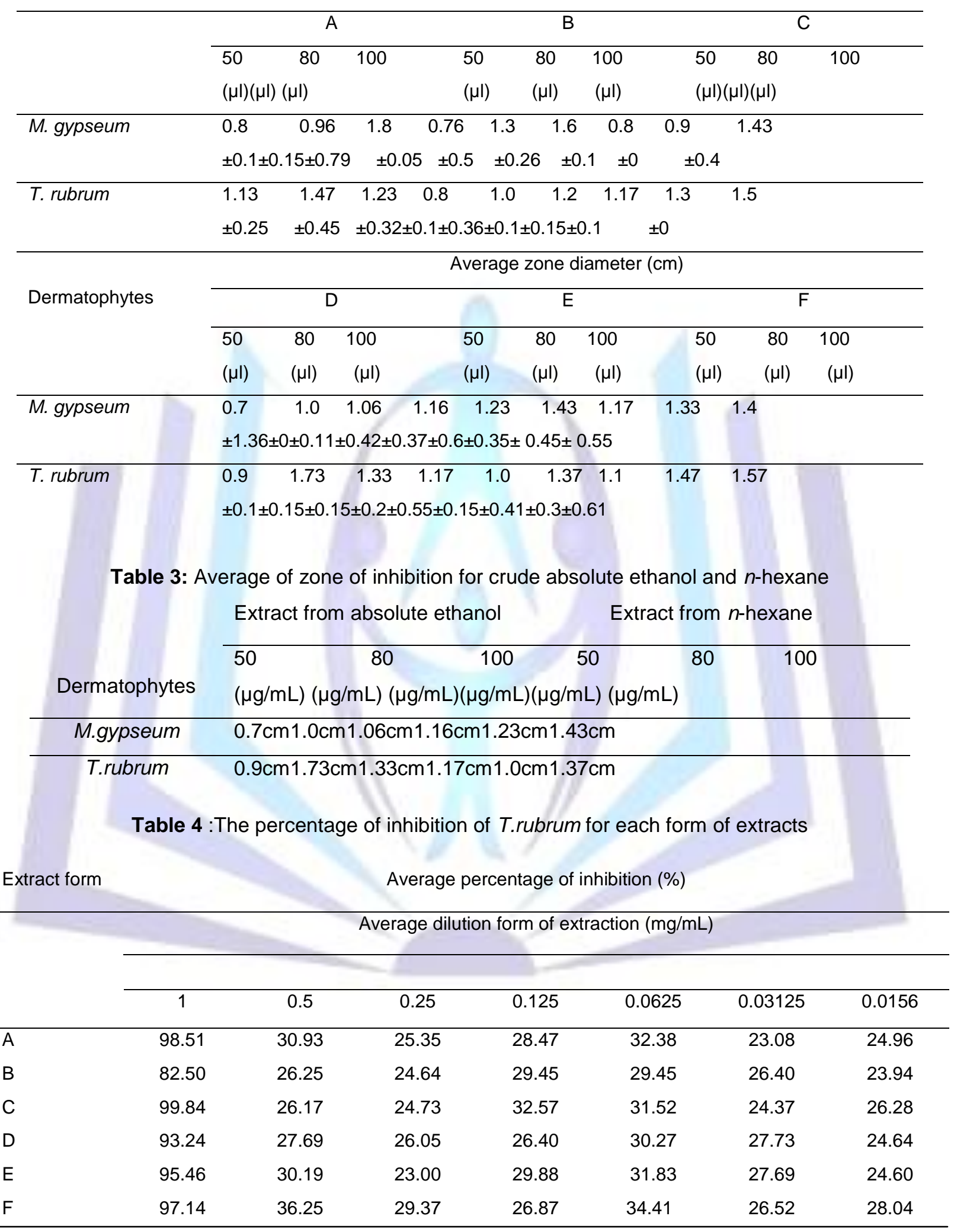

CONTROL 
Table 5 : The percentage of inhibition of M.gypseum for each form of extracts

Extract

Average percentage of inhibition (\%) form

\begin{tabular}{lccccccc}
\hline & \multicolumn{7}{c}{ Average dilution form of extraction $(\mathrm{mg} / \mathrm{mL})$} \\
\cline { 2 - 8 } & 1 & 0.5 & 0.25 & 0.125 & 0.0625 & 0.03125 & 0.0156 \\
\cline { 2 - 8 } & 99.70 & 41.46 & 32.28 & 25.30 & 24.53 & 24.45 & 26.36 \\
\hline A & 79.02 & 36.32 & 31.94 & 31.98 & 31.19 & 30.00 & 30.26 \\
B & 99.73 & 38.76 & 34.20 & 32.13 & 30.00 & 30.30 & 30.70 \\
D & 84.79 & 32.54 & 26.74 & 27.49 & 22.22 & 23.55 & 19.32 \\
E & 84.68 & 71.76 & 33.74 & 31.34 & 31.38 & 28.27 & 27.30 \\
F & 99.28 & 74.79 & 33.55 & 32.65 & 31.27 & 30.40 & 30.40 \\
\hline CONTROL & & & & 82.51 & & &
\end{tabular}

Table 6: Percentage of inhibition of T.rubrum for crude absolute ethanol and $n$-hexane

\begin{tabular}{cccccccc}
\multirow{2}{*}{$\begin{array}{c}\text { Form } \\
\text { extract }\end{array}$} & \multicolumn{7}{c}{ Average percentage of inhibition (\%) } \\
\cline { 2 - 8 } & \multicolumn{7}{c}{ Average dilution form of extract $(\mathrm{mg} / \mathrm{mL})$} \\
\cline { 2 - 8 } & 1 & 0.5 & 0.25 & 0.125 & 0.0625 & 0.03125 & 0.0156 \\
\hline $\begin{array}{c}\text { Crude } \\
\text { absolute } \\
\text { ethanol }\end{array}$ & 93.24 & 27.69 & 26.05 & 26.40 & 30.27 & 27.73 & 24.64 \\
\hline $\begin{array}{c}\text { Crude } n- \\
\text { hexane }\end{array}$ & 95.46 & 30.19 & 23.00 & 29.88 & 31.83 & 27.69 & 24.60 \\
\hline
\end{tabular}

Table 7: Percentage inhibition of M.gypseum for crude absolute ethanol and $n$-hexane

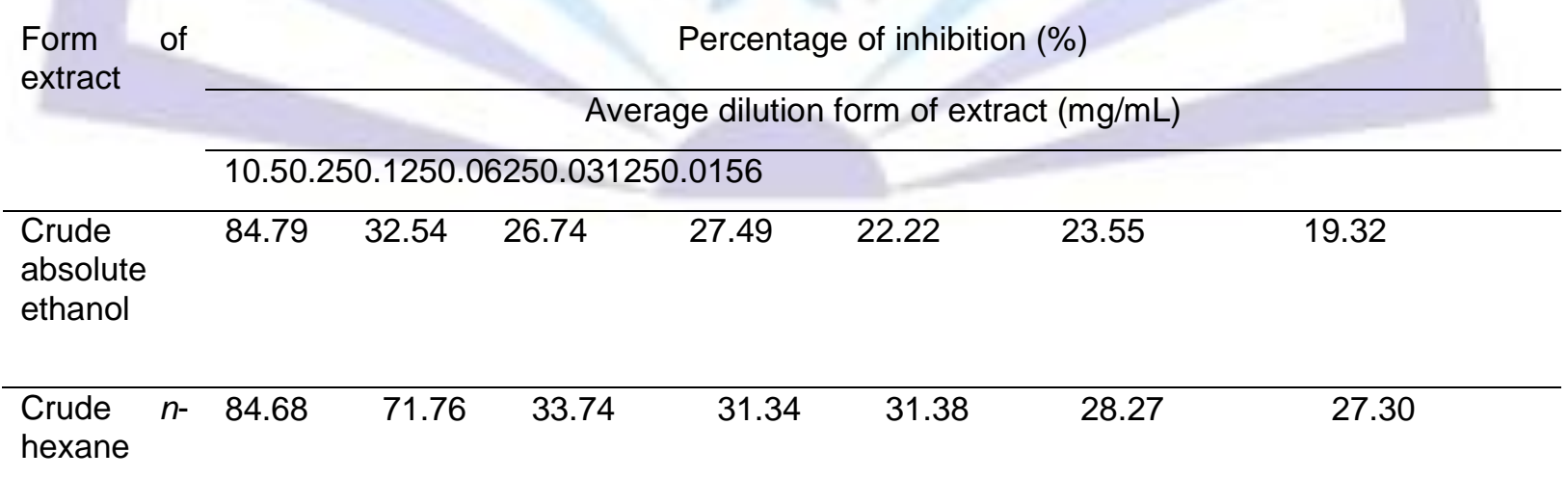

